Research Paper

\title{
Diagnostic Accuracy of MRI for Detecting Cervical Invasion in Patients with Endometrial Carcinoma: A Meta-Analysis
}

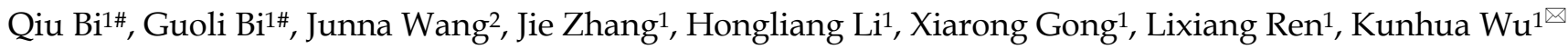 \\ 1. Department of MRI, the First People' s Hospital of Yunnan Province, the Affiliated Hospital of Kunming University of Science and Technology, No. 157 \\ Jinbi Road, Kunming 650032, Yunnan, China. \\ 2. Center of Infectious Diseases, West China Hospital of Sichuan University, No. 37 Guoxue Lane, Wuhou District, Chengdu 610041, Sichuan, China. \\ \#Co-first authors with equal contributions to this work. \\ $\square$ Corresponding author: No. 157 Jinbi Road, Kunming 650032, Yunnan, China. E-mail: khcgz@sina.com; janet.lashley@students.clatsopcc.edu; Fax number: \\ 0871-63638068; Telephone number: 86-13608817635. \\ (1) The author(s). This is an open access article distributed under the terms of the Creative Commons Attribution License (https://creativecommons.org/licenses/by/4.0/). \\ See http://ivyspring.com/terms for full terms and conditions.
}

Received: 2020.09.03; Accepted: 2020.11.02; Published: 2021.01.01

\begin{abstract}
Objectives: To evaluate the diagnostic accuracy of magnetic resonance imaging (MRI) in the preoperative assessment of cervical invasion and to analyse the influence of different imaging protocols in patients with endometrial carcinoma.

Methods: An extensive search of articles about MRI for assessing cervical invasion in patients with endometrial carcinoma was performed on PubMed, Embase, Web of Science, Cochrane Library, and Clinical Trials from January 2000 to July 2020. Two reviewers independently evaluated the methodological quality of each study by using the Quality Assessment of Diagnostic Accuracy Studies-2 (QUADAS-2). Diagnostic accuracy results and additional useful information were extracted. The pooled estimation data was obtained by statistical analysis.

Results: A total of 42 eligible studies were included in the meta-analysis. Significant evidence of heterogeneity was found for detecting cervical invasion $(I 2=74.1 \%, P=0.00$ for sensitivity and $l 2=56.2 \%$, $P=0.00$ for specificity). The pooled sensitivity and specificity of MRI were 0.58 and 0.95 respectively. The use of higher field strength $(3.0 \mathrm{~T})$ demonstrated higher pooled sensitivity $(0.74)$. Using diffusion weighted imaging (DWI) alone presented higher pooled sensitivity $(0.86)$ than using other sequences. The studies that used dynamic contrast-enhanced MRI (DCE-MRI) alone showed higher sensitivity $(0.80)$ and specificity (0.96) than those that used T2-weighted imaging (T2WI) alone.

Conclusions: MRI shows high specificity for detecting cervical infiltration in endometrial carcinoma. Using DWI or a 3.0-T device may improve the pooled sensitivity. DCE-MRI demonstrates higher pooled sensitivity and specificity than T2WI.
\end{abstract}

Key words: endometrial carcinoma; magnetic resonance imaging; diffusion weighted imaging; cervical invasion; meta-analysis

\section{Introduction}

Endometrial carcinoma is one of the most common gynaecological malignancies [1]. Cervical invasion is an important prognostic factor for endometrial carcinoma and is associated with a higher risk of lymph node metastases [2,3]. Hysterectomy and bilateral salpingo-oophorectomy are the primary treatments for endometrial carcinoma
[4]. However, in patients with cervical infiltration, radical hysterectomy or preoperative radiotherapy with bilateral salpingo-oophorectomy and bilateral pelvic-para-aortic lymphadenectomy may be necessary [4]. Consequently, it is important to preoperatively evaluate the cervical involvement when planning treatments. 
Magnetic resonance imaging (MRI) is widely used to detect cervical invasion in endometrial carcinoma and is also more accurate than hysteroscopy [5] and endocervical curettage [6]. MRI has no ionizing radiation and has high soft-tissue resolution for the uterus and cervix. Therefore, in contrast to computed tomography [7] and transvaginal sonography [8], MRI is considered to be the optimal imaging modality for the preoperative assessment of cervical invasion [9]. With the development of functional MRI imaging, diffusion weighted imaging (DWI) and dynamic contrastenhanced MRI (DCE-MRI) are increasingly applied to detect cervical infiltration in endometrial carcinoma [10-14]. Many studies have investigated the accuracy of MRI for detecting cervical invasion [6,12-31]. These studies differ in the MR pulse sequences, magnetic field strength, and number of patients, so the results are diverse. This leads to an ongoing dispute about the accuracy of MRI and the best imaging protocol for evaluating cervical involvement of endometrial carcinoma.

The purpose of the present study was to evaluate the diagnostic accuracy of MRI for detecting cervical invasion and to analyse the effects of different imaging protocols in patients with endometrial carcinoma.

\section{Materials and Methods}

\section{Literature search}

We performed this meta-analysis according to the Preferred Reporting Items for Systematic Reviews-Diagnostic Test Accuracy (PRISMA-DTA) guidelines [32]. A comprehensive literature search of articles pertaining to the accuracy of cervical invasion using MRI in endometrial carcinoma was performed by using the following keywords (including subject word and random word): "endometrial neoplasms", "magnetic resonance imaging", and "cervical". Two authors (G.B., a radiologist with 20 years of experience and Q.B., a radiologist with 5 years of experience) independently conducted the searches on PubMed, Embase, Web of Science, Cochrane Library, and Clinical Trials from January 2000 to May 2020 for English language articles on human subjects. To identify possible missing citations, the reference lists of the relevant articles were manually searched.

\section{Study selection}

The two authors who performed the literature search independently reviewed all the titles, abstracts, and full texts to identify potentially eligible articles. Studies meeting the following criteria were included if: (a) the accuracy for the detection of cervical invasion in endometrial carcinoma was evaluated; (b) the histopathological results after surgical resection were used as the reference standard; and (c) sufficient information was presented to allow for reconstruction of $2 \times 2$ tables. When the data or patient cohorts overlapped in the included studies, we selected the article with the largest number of patients.

\section{Data extraction and processing}

The data on the diagnostic accuracy results and additional useful information in the original studies were collected by two researchers (Q.B. and J.W.) who had 5 years of independent experience in data extraction for diagnostic studies. In cases where the researchers had discrepancies, a consensus was reached after discussion with each other. For each study, the following information was extracted: author name, year of publication, nation, patient age, sample size, number of observers, study design, patient recruitment, blinded to reference, magnetic field, manufacturer, sequences of observing cervical infiltration, depth of cervical invasion, interval between MRI and pathology, and the true-positive, true-negative, false-positive, and false-negative values of MRI in detecting cervical invasion in patients with endometrial carcinoma. When two or more observers were in the same study, the most experienced observer was selected; if their experience was not reported, the first observer was selected. The most contemporary MRI scan (e.g., DWI before DCE-MRI) was preferred when different MR pulse sequences were reported in the same study. When the accuracy of any cervical invasion and stromal invasion was reported separately, the latter was preferred.

\section{Assessment of data quality}

Quality assessment was conducted by the Quality Assessment of Diagnostic Accuracy Studies-2 [33] (QUADAS-2) by two investigators (G.B. and J.Z., a radiologist with 20 years of experience in pelvic imaging) independently. Any disagreements were resolved by discussion with each other. The QUADAS-2 form is composed of four domains: patient selection (assessing methods of patient selection), index test (assessing the index test and how it was conducted and interpreted), reference standard (assessing the reference standard and how it was conducted and interpreted), and flow and timing (assessing any patients who did not receive the index test and/or reference standard or who were excluded from the $2 \times 2$ table).

\section{Statistical analysis}

The analyses were performed by using Review Manager 5.3 (The Nordic Cochrane Centre, Copenhagen, Denmark), MetaDisc 1.4 (Ramón y Cajal Hospital, Madrid, Spain), and Stata 15.1 (StataCorp, 
Texas, USA). The threshold effect was assessed by the Spearman correlation coefficient between the logit of sensitivity and the logit of (1-specificity) [34]. $P$ values $<0.05$ were indicated that the threshold effect existed [34]. Heterogeneity for sensitivity and specificity was explored by using the inconsistency index ( $I^{2}$ value) in forest plots [35]. $I^{2}$ values $\geq 50.0 \%$ are considered to indicate substantial heterogeneity [35]. A fixed-effects model was used to summarize the overall pooled diagnostic results if homogeneity existed. A random-effects model was utilized if heterogeneity existed. Summary receiver operating characteristic (sROC) curves and the area under the curve were used to elucidate the relationship between the sensitivity and specificity. If heterogeneity existed, meta-regression was performed to assess covariates. Several relevant covariates were as follows: patient age ( $\geq 60$ years or $<60$ years), magnetic field (1.5 T or $3.0 \mathrm{~T}$ ), MR pulse sequences, design (prospective or retrospective), blind to reference (yes or unknown), depth of cervical infiltration (stromal invasion or any cervical invasion), and appropriate interval between MRI and pathology (yes or unknown). Sensitivity analyses were performed on the basis of those potential influencing factors of heterogeneity. The publication bias was assessed by using Deeks'funnel plot with $P$ values $<0.05$ [36].

\section{Results}

\section{Literature search and data extraction}

The detailed flowchart summarizing the literature search and selection is given in Figure 1. A total of 1194 records from January 2000 to July 2020 of English language articles on human subjects were found. Two additional records were identified after manual reference checking. After duplicates were removed, 681 unique citations remained. Based on the screening of titles and abstracts, 602 studies were excluded. The full text of 79 studies was reviewed, and 42 eligible studies involving 4196 patients were included in this meta-analysis. Among these 4196 patients, 739 were confirmed to have cervical invasion by surgical pathology. The mean prevalence of endometrial carcinoma with cervical invasion was $17.6 \%$ (range, $4.5 \%-39.5 \%$ ). The details of the principal characteristics of every included study are summarized in Table 1.

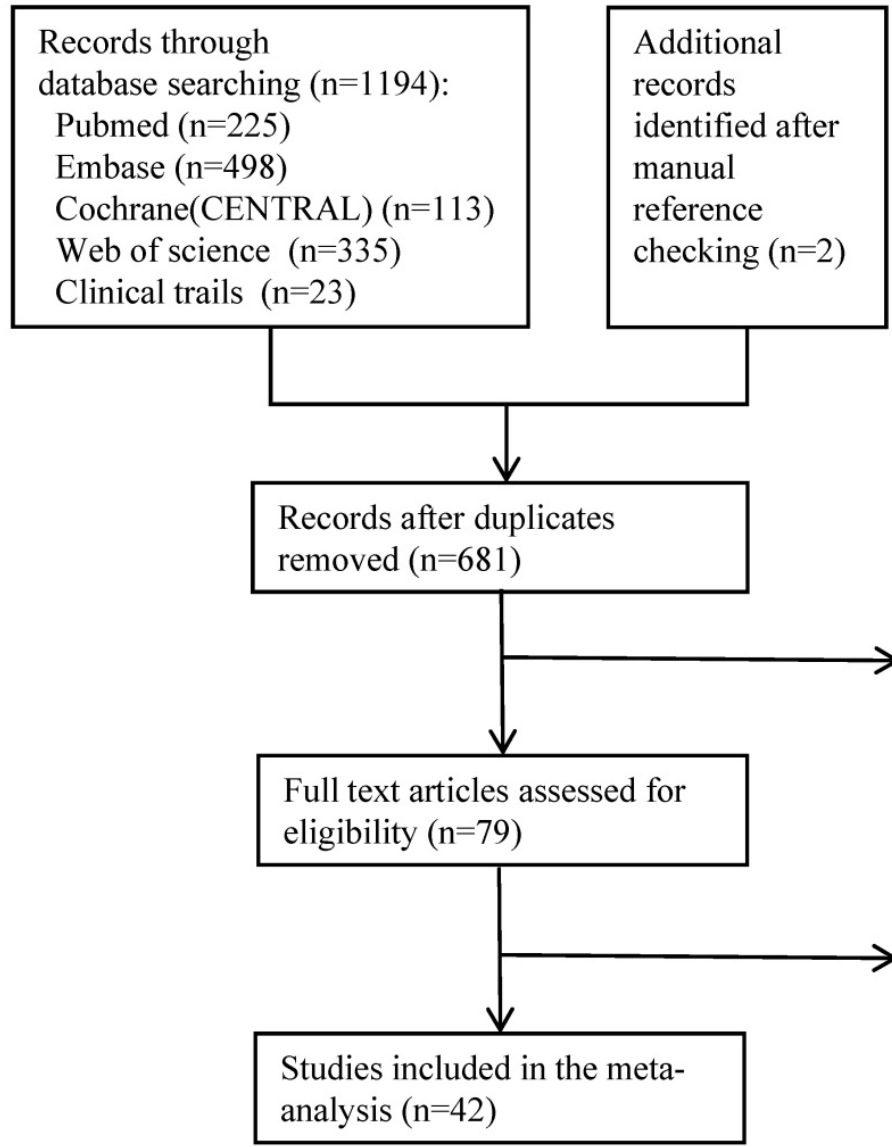

Records excluded based on title or abstract $(n=602)$ : Case report $(\mathrm{n}=98)$

Meta-analysis or review $(\mathrm{n}=188)$

Conference Abstract ( $\mathrm{n}=132)$

Guide, comment, letter, note, book section or editorial $(n=12)$

Not about endometrial cancer, cervical invasion, or MRI $(\mathrm{n}=172)$

Full text articles excluded $(n=37)$ :

Overlapping population $(\mathrm{n}=2)$

Unable to reconstruct $2 \times 2$ table $(n=35)$

Figure 1. Flowchart of the study selection process. 


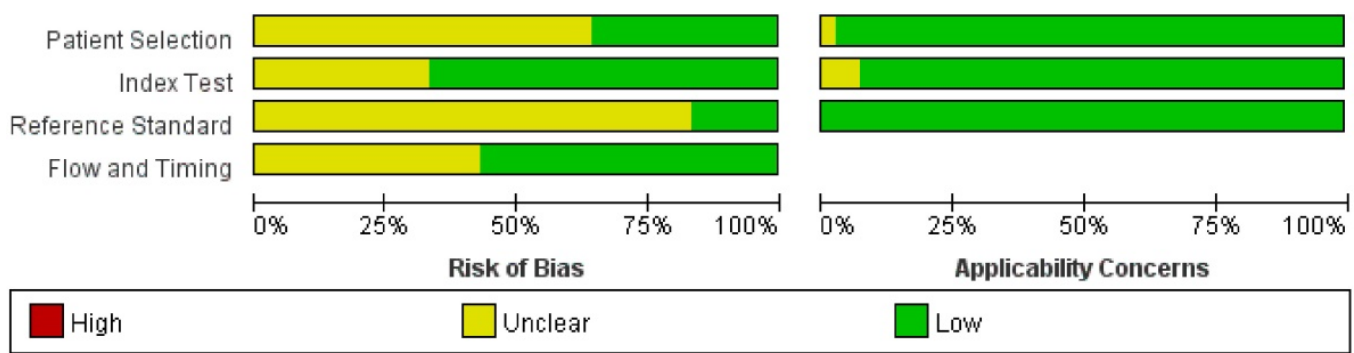

Figure 2. Histogram plot of the Quality Assessment of Diagnostic Accuracy Studies-2 (QUADAS-2) scores of the methodological study quality.

Table 1. Description of Included Studies

\begin{tabular}{|c|c|c|c|c|c|c|c|c|c|c|c|}
\hline Study & Year & Country & Age (y) & Sample size & Design & $\begin{array}{l}\text { Patient } \\
\text { recruitment }\end{array}$ & $\begin{array}{l}\text { Blind to } \\
\text { reference }\end{array}$ & $\begin{array}{l}\text { Magnetic } \\
\text { field }\end{array}$ & Manufacturer & Sequences & $\begin{array}{l}\text { Depth of cervical } \\
\text { invasion }\end{array}$ \\
\hline Morimura & 2000 & Japan & $\mathrm{U}$ & 47 & $\mathrm{R}$ & $\mathrm{U}$ & $\mathrm{U}$ & $\mathrm{U}$ & $\mathrm{U}$ & $\mathrm{T} 2$ & Any cervix \\
\hline Seki & 2000 & Japan & $\mathrm{U}$ & 39 & $\mathrm{P}$ & $\mathrm{U}$ & Yes & $1.5 \mathrm{~T}$ & Siemens & DCE & Any cervix \\
\hline Cunha & 2001 & Portugal & 63.2 & 40 & $\mathrm{P}$ & $\mathrm{U}$ & Yes & $1.0 \mathrm{~T}$ & Philips & $\mathrm{T} 2+\mathrm{DCE}$ & Any cervix \\
\hline Manfredi & 2004 & Italy & 58.8 & 37 & $\mathrm{P}$ & $\mathrm{C}$ & Yes & $1.5 \mathrm{~T}$ & GE & $\mathrm{T} 2$ & Any cervix \\
\hline Akaeda & 2005 & Japan & 56.8 & 21 & $\mathrm{P}$ & $\mathrm{U}$ & Yes & $1.5 \mathrm{~T}$ & Siemens & CO2-VIBE & Any cervix \\
\hline Haider & 2006 & Canada & 56 & 38 & $\mathrm{R}$ & $\mathrm{U}$ & Yes & $1.5 \mathrm{~T}$ & GE & $\mathrm{T} 2$ & Any cervix \\
\hline Nagar & 2006 & UK & 65.5 & 135 & $\mathrm{R}$ & $\mathrm{C}$ & Yes & $1.5 \mathrm{~T}$ & Siemens & $\mathrm{T} 2$ & Stroma \\
\hline Rockall & 2007 & UK & 61 & 84 & $\mathrm{R}$ & $\mathrm{U}$ & Yes & $1.5 \mathrm{~T}$ & GE & DCE & Stroma \\
\hline Vasconcelos & 2007 & Portugal & 68.5 & 101 & $\mathrm{P}$ & $\mathrm{U}$ & Yes & $1.0 \mathrm{~T}$ & Philips & $\mathrm{T} 2+\mathrm{DCE}$ & Any cervix \\
\hline Cabrita & 2008 & Portugal & 64.6 & 162 & $\mathrm{U}$ & $\mathrm{U}$ & $\mathrm{U}$ & $1.5 \mathrm{~T}$ & $\mathrm{U}$ & $\mathrm{U}$ & Any cervix \\
\hline Cicinelli & 2008 & Italy & 67.3 & 100 & $\mathrm{U}$ & $\mathrm{C}$ & Yes & $1.5 \mathrm{~T}$ & Philips & $\mathrm{T} 2$ & Any cervix \\
\hline Sanjuan & 2008 & Spain & $\mathrm{U}$ & 72 & $\mathrm{R}$ & $\mathrm{C}$ & $\mathrm{U}$ & $1.0 \mathrm{~T}$ & Siemens & $\mathrm{T} 2+\mathrm{DCE}$ & Any cervix \\
\hline Savelli & 2008 & Italy & 63 & 74 & $\mathrm{P}$ & $\mathrm{C}$ & Yes & $\mathrm{U}$ & $\mathrm{U}$ & $\mathrm{T} 2$ & Any cervix \\
\hline Hori & 2009 & Japan & 58.7 & 30 & $\mathrm{P}$ & C & Yes & $3.0 \mathrm{~T}$ & GE & $\mathrm{T} 2$ & Any cervix \\
\hline Undurraga & 2009 & Switzerland & 69.5 & 108 & $\mathrm{R}$ & $\mathrm{C}$ & Yes & $1.5 \mathrm{~T}$ & $\mathrm{U}$ & $\mathrm{T} 2+\mathrm{CE}$ & Stroma \\
\hline Celik & 2010 & Turkey & 58.9 & 64 & $\mathrm{P}$ & $\mathrm{C}$ & Yes & $1.5 \mathrm{~T}$ & Siemens & $\mathrm{U}$ & Any cervix \\
\hline Emlik & 2010 & Turkey & $\mathrm{U}$ & 53 & $\mathrm{P}$ & $\mathrm{C}$ & Yes & $1.5 \mathrm{~T}$ & Siemens & DCE & Any cervix \\
\hline Duncan & 2012 & UK & $\mathrm{U}$ & 748 & $\mathrm{U}$ & $\mathrm{U}$ & $\mathrm{U}$ & $\mathrm{U}$ & $\mathrm{U}$ & $\mathrm{U}$ & Stroma \\
\hline Haldorsen & 2012 & Norway & 66 & 146 & $\mathrm{P}$ & $\mathrm{U}$ & Yes & $1.5 \mathrm{~T}$ & Siemens & $\mathrm{U}$ & Stroma \\
\hline Tong & 2012 & China & 52 & 168 & $\mathrm{R}$ & $\mathrm{C}$ & $\mathrm{U}$ & $1.5 \mathrm{~T}$ & GE & $\mathrm{T} 2+\mathrm{DCE}$ & Stroma \\
\hline Zamani & 2012 & Iran & 53.3 & 54 & $\mathrm{U}$ & $\mathrm{U}$ & Yes & $1.5 \mathrm{~T}$ & $\mathrm{U}$ & $\mathrm{U}$ & Stroma \\
\hline Aly & 2013 & Egypt & 59 & 40 & $\mathrm{U}$ & $\mathrm{U}$ & Yes & $1.5 \mathrm{~T}$ & GE & DCE & Stroma \\
\hline Antonsen & 2013 & Denmark & 65 & 226 & $\mathrm{P}$ & $\mathrm{C}$ & Yes & $1.5 \mathrm{~T}$ & Philips & $\mathrm{U}$ & Any cervix \\
\hline Foti & 2013 & Italy & 62 & 20 & $\mathrm{P}$ & $\mathrm{C}$ & Yes & $1.5 \mathrm{~T}$ & GE & $\mathrm{T} 2$ & Any cervix \\
\hline Hahn & 2013 & Korea & 53.1 & 131 & $\mathrm{R}$ & $\mathrm{U}$ & Yes & $1.5 \mathrm{~T}$ & Philips & $\mathrm{U}$ & Stroma \\
\hline Hori & 2013 & Japan & 57.6 & 71 & $\mathrm{P}$ & C & Yes & $3.0 \mathrm{~T}$ & Philips & $\mathrm{T} 2+\mathrm{DWI}$ & Stroma \\
\hline Kitajima & 2013 & Japan & 62.4 & 30 & $\mathrm{R}$ & $\mathrm{U}$ & Yes & $1.5 \mathrm{~T}$ & GE & $\mathrm{U}$ & Stroma \\
\hline Gitte & 2013 & Denmark & $\mathrm{U}$ & 143 & $\mathrm{P}$ & $\mathrm{U}$ & Yes & $1.5 \mathrm{~T}$ & GE & $\mathrm{U}$ & Any cervix \\
\hline Koplay & 2014 & Turkey & 58 & 58 & $\mathrm{P}$ & $\mathrm{C}$ & Yes & $1.5 \mathrm{~T}$ & Siemens & DWI & Any cervix \\
\hline Teng & 2015 & China & 57.9 & 167 & $\mathrm{R}$ & $\mathrm{U}$ & Yes & $1.5 \mathrm{~T}$ & GE & $\mathrm{T} 2+\mathrm{DCE}$ & Any cervix \\
\hline Yin & 2015 & China & 54.6 & 98 & $\mathrm{R}$ & $\mathrm{U}$ & Yes & $3.0 \mathrm{~T}$ & $\mathrm{U}$ & $\mathrm{T} 2+\mathrm{DCE}$ & Any cervix \\
\hline Zamani & 2015 & Iran & $\mathrm{U}$ & 68 & $\mathrm{P}$ & $\mathrm{U}$ & Yes & $\mathrm{U}$ & $\mathrm{U}$ & $\mathrm{U}$ & Stroma \\
\hline Angioli & 2016 & Italy & 53 & 41 & $\mathrm{P}$ & $\mathrm{U}$ & Yes & $1.5 \mathrm{~T}$ & GE & DWI & Any cervix \\
\hline Chan & 2016 & China & 55.2 & 90 & $\mathrm{R}$ & $\mathrm{U}$ & Yes & $1.5 \mathrm{~T}$ & Siemens & $\mathrm{T} 2+\mathrm{DCE}$ & Stroma \\
\hline Shrivastava & 2016 & India & 52.8 & 36 & $\mathrm{R}$ & $\mathrm{U}$ & Yes & $1.5 \mathrm{~T}$ & Philips & $\mathrm{U}$ & Stroma \\
\hline Lin & 2017 & China & 56 & 83 & $\mathrm{U}$ & $\mathrm{C}$ & Yes & $3.0 \mathrm{~T}$ & Siemens & DWI & Stroma \\
\hline Rahmani & 2018 & Iran & $\mathrm{U}$ & 27 & $\mathrm{P}$ & $\mathrm{U}$ & Yes & $3.0 \mathrm{~T}$ & Siemens & $\mathrm{U}$ & Any cervix \\
\hline $\mathrm{Xu}$ & 2018 & China & 51.89 & 88 & $\mathrm{R}$ & $\mathrm{U}$ & $\mathrm{U}$ & $\mathrm{U}$ & $\mathrm{U}$ & $\mathrm{U}$ & Any cervix \\
\hline Yildirim & 2018 & Turkey & 61.1 & 40 & $\mathrm{P}$ & $\mathrm{U}$ & Yes & $1.5 \mathrm{~T}$ & Philips & $\mathrm{U}$ & Any cervix \\
\hline Ytre-Hauge & 2018 & Norway & 67 & 178 & $\mathrm{P}$ & $\mathrm{C}$ & Yes & $1.5 \mathrm{~T}$ & Siemens & $\mathrm{U}$ & Stroma \\
\hline Goel & 2019 & India & 60.2 & 58 & $\mathrm{P}$ & $\mathrm{U}$ & Yes & $1.5 \mathrm{~T}$ & GE & $\mathrm{T} 2+\mathrm{DCE}$ & Any cervix \\
\hline Yang & 2019 & China & 54.1 & 182 & $\mathrm{R}$ & $\mathrm{U}$ & Yes & $3.0 \mathrm{~T}$ & GE & $\mathrm{T} 2$ & Any cervix \\
\hline
\end{tabular}

U, unknown; P, prospective; R, retrospective; C, consecutive; CE, contrast-enhanced MRI; DCE, dynamic contrast-enhanced MRI; DWI, diffusion weighted imaging; $\mathrm{CO} 2$-VIBE, $\mathrm{CO}_{2}$-volumetric interpolated breathhold examination.

\section{Quality assessment and publication bias}

Figure 2 shows the methodological quality graph of the evaluation of the risk of bias and applicability concerns of the selected studies, according to the evaluation based on QUADAS-2.
Regarding the risk of bias and the patient selection domain, 14 studies explicitly reported that the patients were consecutive $[10,12,13,16,21,23,25-28,31$, 37-39], and the remaining 28 studies only reported the start and end times of patient recruitment $[5,6,8,11$, 
$14,15,17-20,22,24,29,30,40-53]$. Concerning the index test domain, 6 studies did not report that histopathology was blinded from the MRI findings [5,22, $23,27,40,45]$. Eleven studies did not present the threshold for defining cervical invasion $[5,8,15,17,22$, $37,38,45,48,51,52]$. For the reference standard domain, only 7 studies explicitly stated that pathology results were blinded to MRI findings [18,20,24,26,31,38,41], the remaining 35 studies lacked information for the reference domain. In relation to the flow and timing domain, twenty-four studies reported an appropriate interval between the MRI and pathological examination $[5,6,8,10,12-16,18-21,23,24,26,30,31,38,39$, $41,44,45,50]$, and the remaining 18 studies did not report the interval. All studies applied pathological evaluation of the removed uterus except for one study where the evaluation was not reported [22].

The slope coefficients for the Deeks'funnel plot for MRI in assessing cervical invasion in endometrial carcinoma are presented in Figure 3. Publication bias was detected in the funnel plots for the diagnosis of cervical invasion $(P=0.01)$.

\section{Diagnostic accuracy}

The threshold effect did not exist for detecting cervical invasion (Spearman correlation coefficient $=$ $-0.282, P=0.070$ ). Figure 4 shows the forest plots of the sensitivity and specificity of MRI for detecting cervical invasion, which showed significant evidence of heterogeneity $\left(I^{2}=74.1 \%, P=0.000\right.$ for sensitivity and $I^{2}=56.2 \%, P=0.000$ for specificity). The pooled sensitivity, specificity, positive likelihood ratio, negative likelihood ratio, and diagnostic odds ratios for the diagnostic accuracy of MRI in detecting cervical invasion were 0.58 (95\% confidence interval [CI] 0.55-0.62), 0.95 (95\% CI 0.94-0.95), 9.37 (95\% CI 7.78-11.28), 0.43 (95\% CI 0.36-0.51), and 29.68 (95\% CI 21.16-41.63), respectively. On the basis of sROC (Figure 5), the area under the curve was 0.94. Fagan nomograms showed that the pre-test probability of cervical invasion was $18 \%$, and the corresponding positive post-test probability and negative post-test probability were $73 \%$ and $8 \%$, respectively (Figure 6).

\section{Meta-regression and sensitivity analyses}

Meta-regression showed that patient age, magnetic field, MR pulse sequences, design, blinding method, depth of cervical infiltration, and interval between MRI and pathology did not explain the heterogeneity observed for sensitivity and specificity (Table 2).

Table 2. The Results of Meta-Regression of MRI

\begin{tabular}{|c|c|c|c|c|c|}
\hline Variable & Coefficient & $\begin{array}{l}\text { Standard } \\
\text { error }\end{array}$ & $P$ value & $\begin{array}{l}\text { Diagnostic } \\
\text { odd ratio }\end{array}$ & $95 \% \mathrm{CI}$ \\
\hline Age & 0.402 & 0.2274 & 0.0850 & 1.49 & $(0.94-2.37)$ \\
\hline Design & -0.082 & 0.2363 & 0.7296 & 0.92 & $(0.57-1.49)$ \\
\hline Blind to reference & 0.444 & 0.4159 & 0.2926 & 1.56 & $(0.67-3.61)$ \\
\hline Magnetic field & 0.383 & 0.2181 & 0.0865 & 1.47 & $(0.94-2.28)$ \\
\hline Sequences & 0.109 & 0.0660 & 0.1080 & 1.11 & $(0.98-1.27)$ \\
\hline Depth of cervical invasion & -0.043 & 0.3423 & 0.8996 & 0.96 & $(0.48-1.91)$ \\
\hline $\begin{array}{l}\text { Interval between MRI and } \\
\text { pathology }\end{array}$ & -0.309 & 0.3274 & 0.3518 & 0.73 & $(0.38-1.42)$ \\
\hline
\end{tabular}

CI, confidence interval.

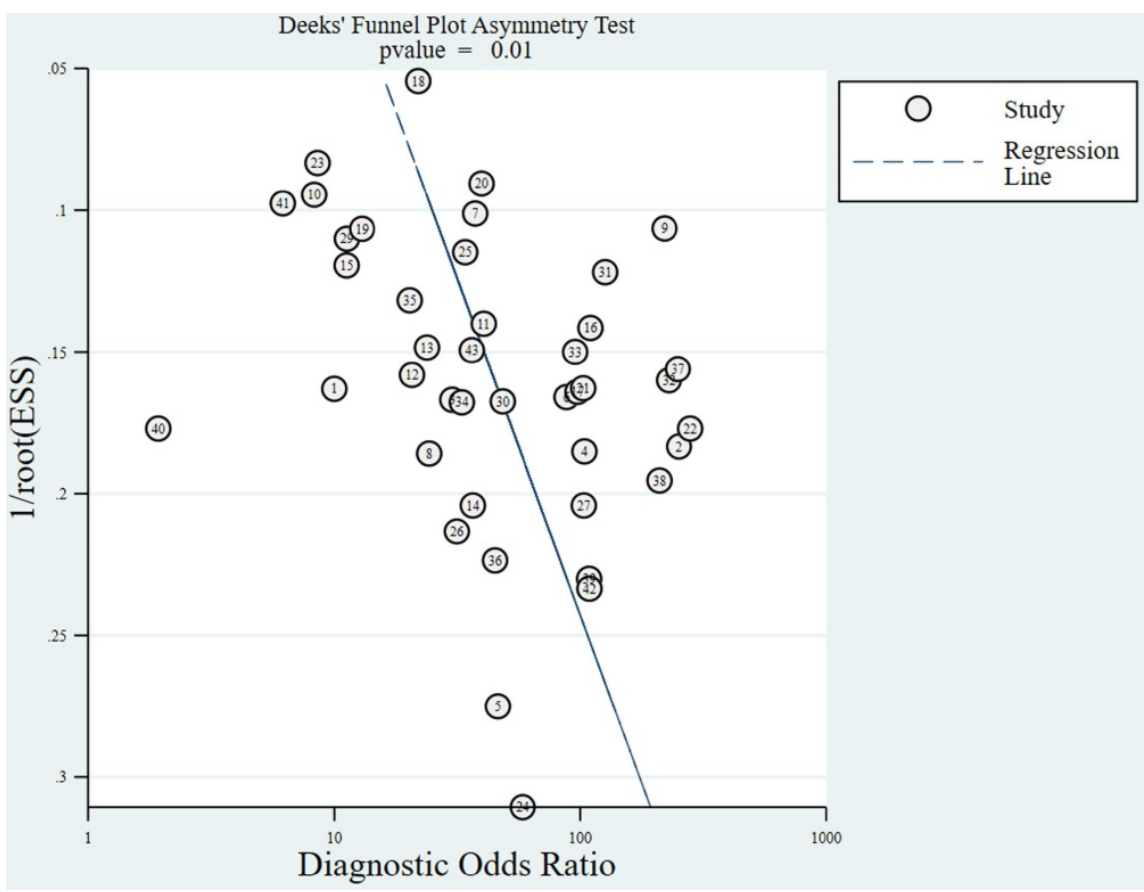

Figure 3. Deeks'funnel plot for evaluating cervical invasion in endometrial carcinoma. A value of $P<0.05$ was considered to indicate significant publication bias. The numbers in circles represent the study numbers. ESS, effective sample size. 

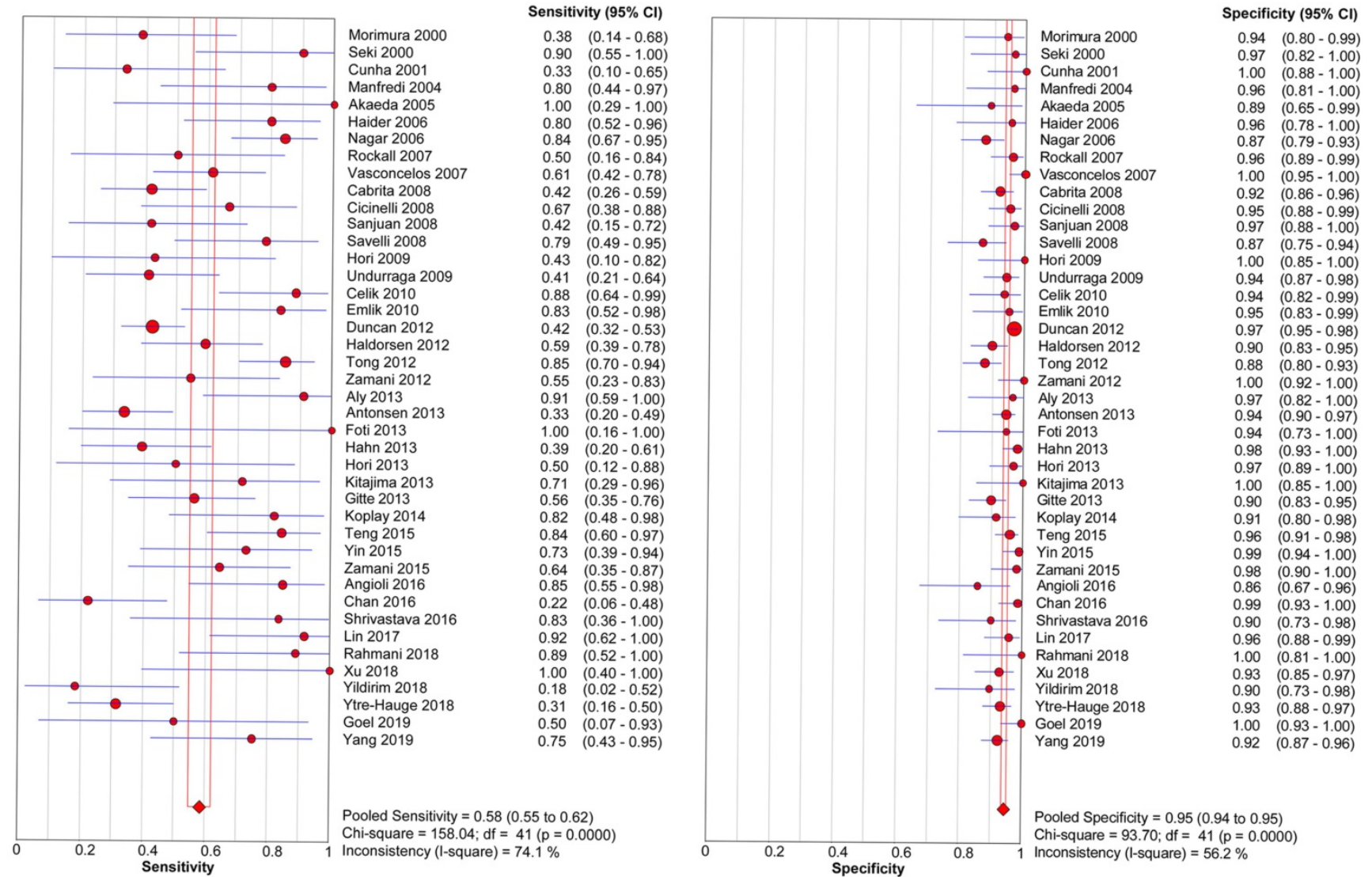

Figure 4. Forest plots show the pooled sensitivity and specificity of MRI for detecting cervical invasion in endometrial carcinoma. 12 values $\geq 50.0 \%$ are considered to indicate substantial heterogeneity in each study. $\mathrm{Cl}$, confidence interval.

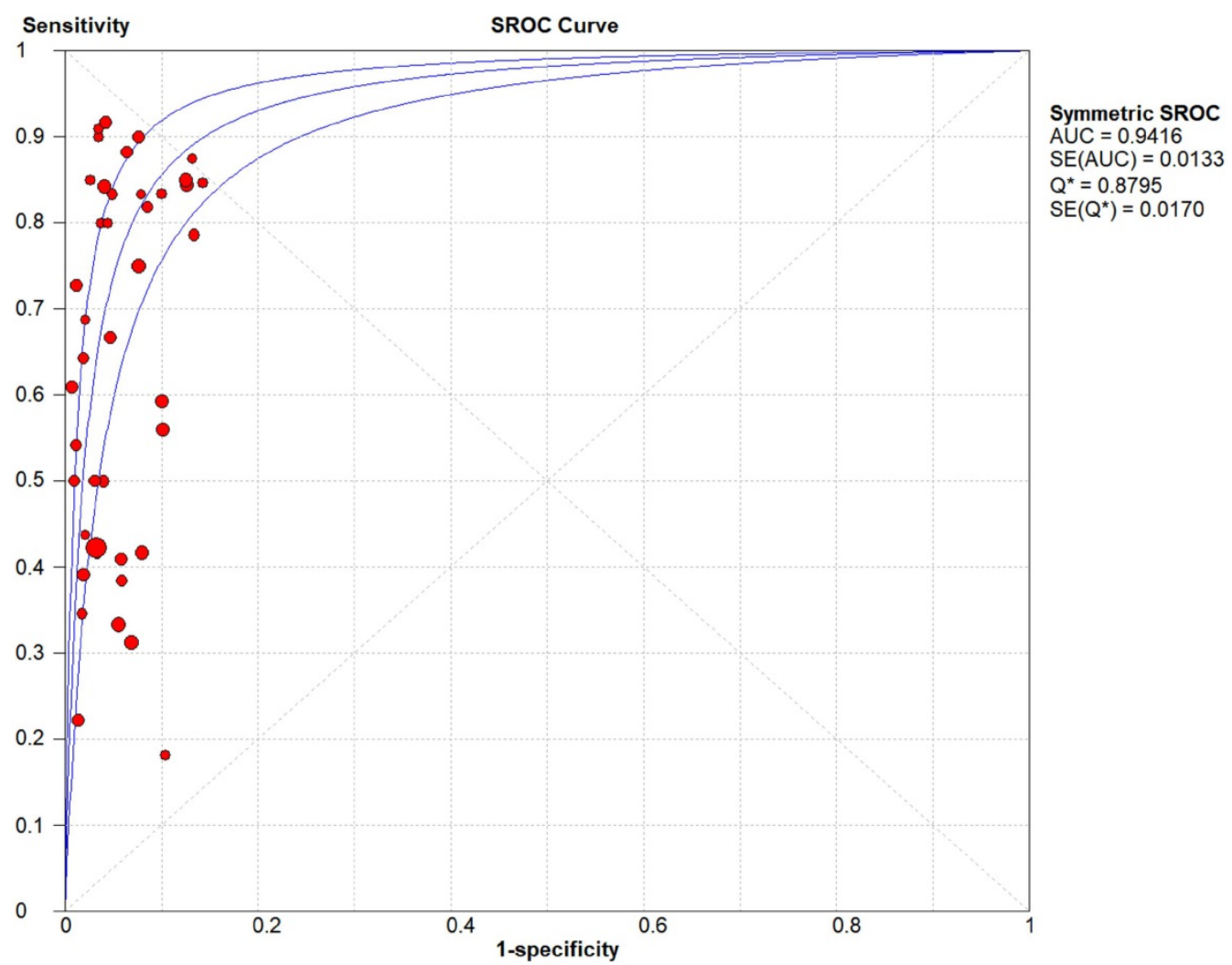

Figure 5. Summary receiver operating characteristic (sROC) curves of MRI for detecting cervical invasion in endometrial carcinoma. AUC, area under the curve. 
Table 3. Sensitivity Analyses Performed for Subgroups of Studies

\begin{tabular}{|c|c|c|c|c|c|c|}
\hline Analysis & Number of studies & Sensitivity & Specificity & PLR & NLR & DOR \\
\hline Overall & 42 & $0.58(0.55-0.62)$ & $0.95(0.94-0.95)$ & 9.37 (7.78-11.28) & $0.43(0.36-0.51)$ & $29.68(21.16-41.63)$ \\
\hline \multicolumn{7}{|l|}{ Age (y) } \\
\hline$\geq 60$ & 15 & $0.51(0.45-0.56)$ & $0.93(0.92-0.95)$ & $6.73(5.18-8.74)$ & $0.54(0.44-0.67)$ & $15.54(9.49-25.45)$ \\
\hline$<60$ & 19 & $0.72(0.66-0.78)$ & $0.94(0.93-0.96)$ & $10.95(8.61-13.94)$ & $0.27(0.18-0.42)$ & 58.71 (37.51-91.89) \\
\hline \multicolumn{7}{|l|}{ Design } \\
\hline Prospective & 21 & $0.58(0.52-0.64)$ & $0.94(0.92-0.95)$ & $7.96(5.93-10.68)$ & $0.43(0.33-0.56)$ & $26.78(15.43-46.50)$ \\
\hline Retrospective & 15 & $0.64(0.58-0.70)$ & $0.94(0.93-0.95)$ & 9.62 (7.53-12.30) & $0.38(0.26-0.54)$ & $35.25(23.09-53.81)$ \\
\hline \multicolumn{7}{|l|}{ Blind to reference } \\
\hline Yes & 36 & $0.61(0.57-0.65)$ & $0.94(0.93-0.95)$ & $9.81(7.82-12.30)$ & $0.39(0.32-0.49)$ & $34.44(23.00-51.57)$ \\
\hline Unknown & 6 & $0.51(0.44-0.59)$ & $0.95(0.93-0.96)$ & $8.76(6.21-12.35)$ & $0.53(0.39-0.72)$ & 19.45 (11.01-34.34) \\
\hline \multicolumn{7}{|l|}{ Magnetic field } \\
\hline $3.0 \mathrm{~T}$ & 6 & $0.74(0.60-0.84)$ & $0.96(0.93-0.97)$ & $16.22(8.69-30.25)$ & $0.33(0.19-0.58)$ & $68.56(28.18-166.78)$ \\
\hline $1.5 \mathrm{~T}$ & 28 & $0.60(0.56-0.65)$ & $0.93(0.92-0.94)$ & $8.15(6.61-10.04)$ & $0.40(0.31-0.51)$ & $27.08(17.60-41.66)$ \\
\hline $1.0 \mathrm{~T}$ & 3 & $0.51(0.37-0.65)$ & $0.99(0.96-1.00)$ & $19.99(5.73-69.76)$ & $0.54(0.39-0.76)$ & 39.81 (9.15-173.19) \\
\hline \multicolumn{7}{|l|}{ MR pulse sequences } \\
\hline DWI & 3 & $0.86(0.71-0.95)$ & $0.92(0.87-0.96)$ & $10.18(4.97-20.86)$ & $0.16(0.07-0.37)$ & $61.42(19.65-191.93)$ \\
\hline DCE & 4 & $0.80(0.65-0.91)$ & $0.96(0.92-0.98)$ & $17.65(8.10-38.48)$ & $0.21(0.07-0.61)$ & $78.46(24.60-250.18)$ \\
\hline $\mathrm{T} 2$ & 9 & $0.73(0.64-0.80)$ & $0.92(0.89-0.94)$ & $8.34(6.14-11.33)$ & $0.33(0.21-0.51)$ & $34.57(19.48-61.35)$ \\
\hline $\mathrm{T} 2+\mathrm{DCE}$ & 9 & $0.60(0.52-0.67)$ & $0.96(0.94-0.97)$ & $14.35(7.78-26.46)$ & $0.45(0.30-0.67)$ & $42.38(20.56-87.35)$ \\
\hline \multicolumn{7}{|c|}{ Depth of cervical invasion } \\
\hline Stromal invasion & 16 & $0.55(0.50-0.61)$ & $0.95(0.94-0.96)$ & $9.29(7.01-12.30)$ & $0.46(0.36-0.59)$ & $25.98(16.52-40.85)$ \\
\hline Any cervical invasion & 26 & $0.61(0.56-0.66)$ & $0.94(0.93-0.95)$ & $9.53(7.38-12.32)$ & $0.39(0.30-0.50)$ & $33.69(20.43-55.56)$ \\
\hline \multicolumn{7}{|c|}{ Interval between MRI and pathology } \\
\hline Appropriate & 24 & $0.59(0.54-0.63)$ & $0.94(0.93-0.95)$ & $9.10(7.00-11.83)$ & $0.42(0.32-0.54)$ & $30.02(17.73-50.80)$ \\
\hline Unknown & 18 & $0.58(0.53-0.64)$ & $0.95(0.94-0.96)$ & $9.86(7.68-12.65)$ & $0.43(0.34-0.54)$ & $28.66(20.11-40.86)$ \\
\hline
\end{tabular}

PLR, positive likelihood ratio; NLR, negative likelihood ratio; DOR, diagnostic odds ratios; DWI, diffusion weighted imaging; DCE, dynamic contrast-enhanced MRI. Data in parentheses are $95 \%$ confidence interval.

Bold fonts, indicating $I^{2}$ values $<50.0 \%$.

Table 3 presents the results of the sensitivity analyses performed for the different subgroups. Overall, several differences were observed for the sensitivity and specificity estimates in sensitivity analyses, and the forest plots of sensitivity and specificity are presented in Figure 7-8. Studies with higher field strength $(3.0 \mathrm{~T})$ had higher pooled sensitivity $(0.74 ; 95 \% \mathrm{CI}: 0.60-0.84)$ than studies with a $1.5-\mathrm{T}$ device $(0.60 ; 95 \% \mathrm{CI}: 0.56-0.65)$ or 1.0 -T device (0.51; 95\% CI: 0.37-0.65). Additionally the higher the field strength was, the higher the pooled sensitivity. However, the pooled specificity was lower when using a 3.0-T device (0.96; 95\% CI: 0.93-0.97) than when using a 1.0-T device (0.99; 95\% CI: 0.96-1.00). Regarding the MR pulse sequences for observing cervical invasion, the three studies $[10,16,17]$ that used DWI alone had higher sensitivity $(0.86 ; 95 \%$ CI: $0.71-0.95)$ than the studies that used DCE-MRI $(0.80$; 95\% CI: 0.65-0.91) or T2-weighted imaging (T2WI) (0.73; 95\% CI: 0.64-0.80) alone. The four studies $[11,13,14,43]$ that used DCE-MRI alone presented higher sensitivity $(0.80 ; 95 \%$ CI: $0.65-0.91)$ and specificity (0.96; 95\% CI: 0.92-0.98) than those studies that used T2WI alone. T2WI combined with DCE-MRI did not improve diagnostic performance in comparison with DCE-MRI alone. For the depth of cervical invasion, the pooled sensitivity and specificity of MRI were 0.55 (95\% CI $0.50-0.61)$ and 0.95 (95\% CI 0.94-0.96) respectively for assessing stromal invasion in endometrial carcinoma.

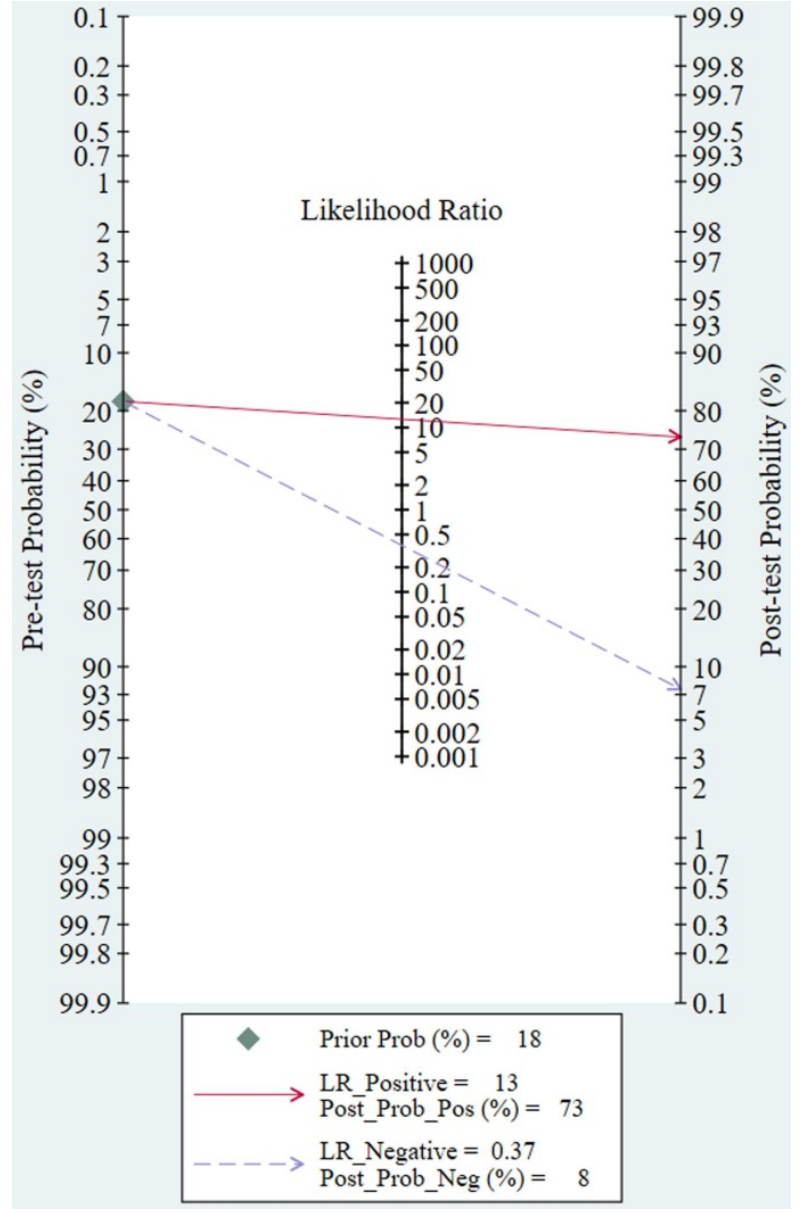

Figure 6. The Fagan nomogram shows the pre-test probability, positive post-test probability, and negative post-test probability of MRI for assessing cervical involvement in endometrial carcinoma. LR, likelihood ratio; Prob, probability. 

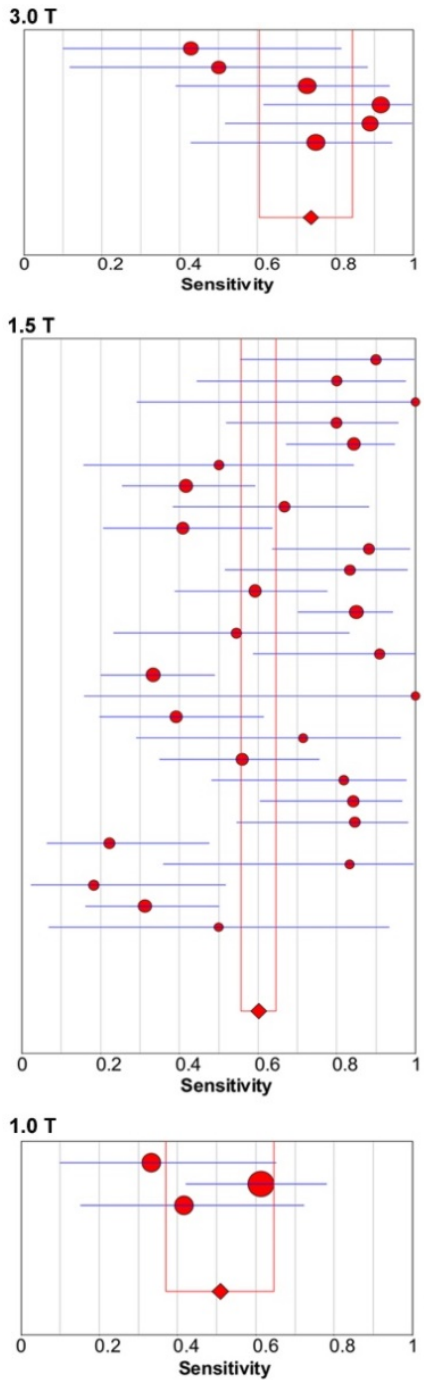

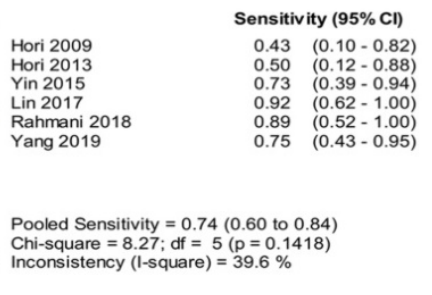

Sensitivity $(95 \% \mathrm{Cl})$

Seki 2000 Akaeda 2005 Haider 2006 Nagar 2006 Rockall 2007
Cabrita 2008 Cicinelli 2008 Undurraga 2009 Celik 2010 Emlik 2010 Haldorsen 2012 Tong 2012 Zamani 2012 Aly 2013 Antonsen 2013
Foti 2013 Foti 2013 Kitajima 2013 Gitte 2013 Koplay 2014 Teng 2015 Angioli 2016 Chan 2016 Yildirim 2018
Yrivastava 2016 Yildirim 2018
Ytre-Hauge 2018
Goel 2019

Pooled Sensitivity $=0.60$ (0.56 to 0.65 ) Pooled Sensitivity $=0.60(0.56$ to 0.65$)$ Chi-square = 119.47; $\mathrm{df}=27(\mathrm{p}=0.00$
Inconsistency $(\mathrm{l}$-square $)=77.4 \%$

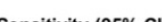

Cunha 2001 asconcelos 2007

Pooled Sensitivity $=0.51(0.37$ to 0.65$)$ Chi-square $=3.27 ;$ df $=2(p=0.1949)$ Chi-square $=3.27 ; \mathrm{df}=2(\mathrm{p}=0.1949)$
Inconsistency $(\mathrm{l}$-square $)=38.8 \%$
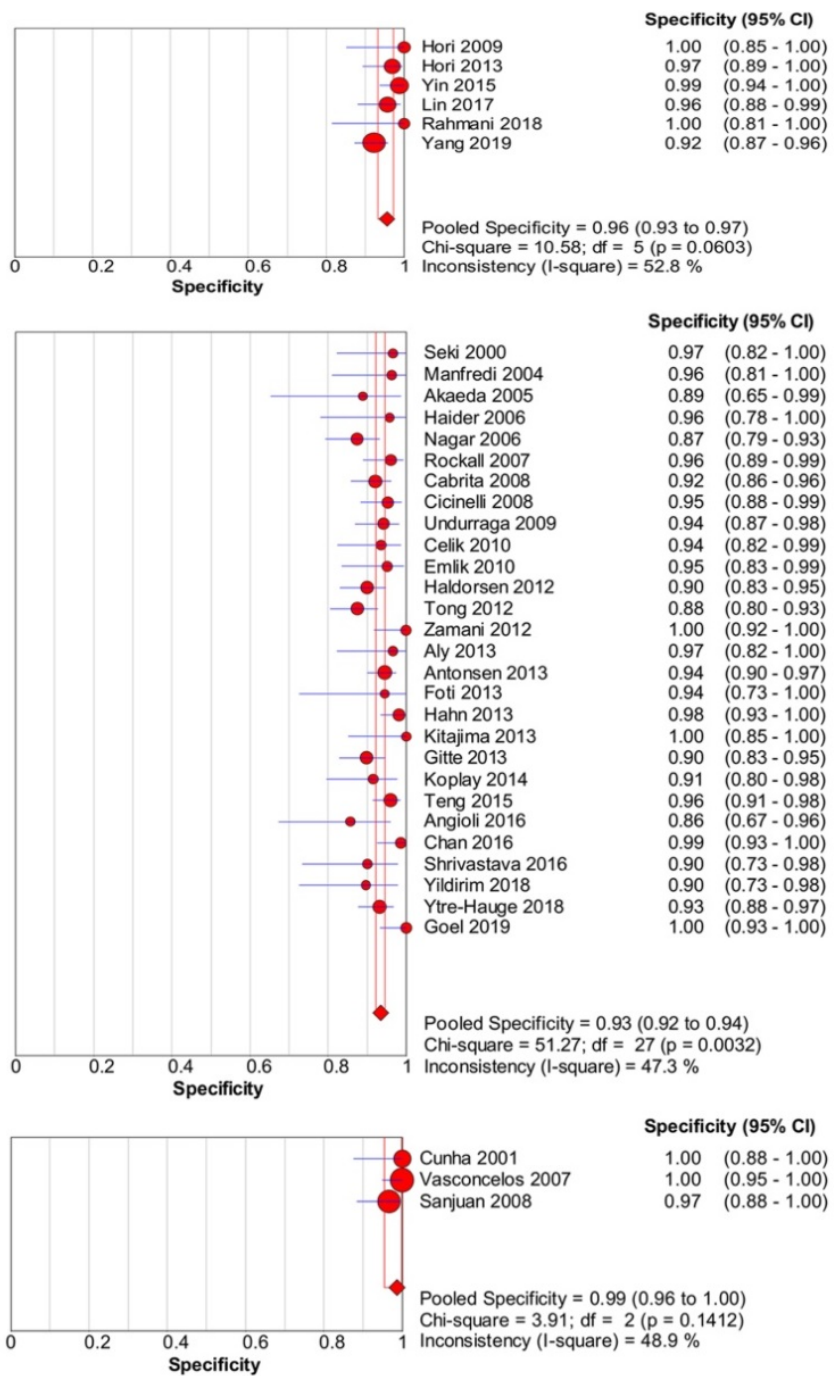

Figure 7. Forest plots of pooled sensitivity and specificity of using a 3.0-T device, 1.5-T device, and 1.0-T device for assessing cervical involvement in endometrial carcinoma. Cl, confidence interval.

\section{Discussion}

This meta-analysis demonstrated high pooled specificity of MRI for detecting any cervical infiltration and stromal invasion in patients with endometrial carcinoma. Sensitivity analyses revealed that magnetic field and MR pulse sequences were helpful in explaining the heterogeneity observed for the sensitivity and specificity of MRI for detecting cervical invasion.

The clinical management and the prognosis of endometrial carcinoma are closely related to cervical invasion [4]. Using a preoperative technique to detect cervical invasion of endometrial carcinoma may be helpful to reduce the scope of operation, minimize costs, and offer fertility-preserving treatment options for young women without cervical invasion [54]. MRI is considered the best non-invasive method for the preoperative staging of endometrial carcinoma [9]. In this meta-analysis, MRI showed low sensitivity (0.58) and high specificity (0.95) for detecting cervical invasion. This finding is similar to that in a previous meta-analysis [55]. Moreover, further sensitivity analyses of magnetic field strength were performed in our meta-analysis. We found that studies with higher field strength $(3.0 \mathrm{~T})$ had higher sensitivity $(0.74)$ than studies with a 1.5-T device (0.60) or 1.0-T device (0.51). Hori et al [25] discovered that 3.0-T imaging improved the tumour signal-to-noise ratio by approximately $12 \%$ compared with that of $1.5-\mathrm{T}$ imaging. The main reason for this result is that the signal-to-noise ratio is influenced by the magnetic field strength, with higher fields having a better signal-to-noise ratio. Hence, a 3.0-T device can provide better quality MRI and demonstrate higher pooled sensitivity (0.74) for detecting cervical invasion in endometrial carcinoma. However, there are some problems associated with 3.0-T imaging, particularly of the pelvis, such as a larger susceptibility effect and larger chemical shift [25]. 
These factors may affect the diagnostic accuracy for detecting cervical infiltration in endometrial carcinoma. As a consequence, the pooled specificity was not the highest for the studies using a 3.0-T device (0.96).

T2WI is a conventional MR pulse sequence and one of the best MRI protocols for staging in patients with endometrial carcinoma according to the Updated Guidelines of the European Society of Urogenital Radiology [56]. On T2WI, cervical invasion is defined as a mass within the endocervical canal and/or disruption of the normal cervical stroma [25]. The normal cervical stroma appears hypointense on T2WI due to its rich fibrous tissue, and endometrial carcinoma appears hyperintense, leading to high contrast resolution [31]. Consequently, MRI shows high specificity for detecting cervical invasion. A high specificity means the misdiagnosis rate (false positive rate) is low, and indicates to be good at ruling out cervical invasion. Therefore, if MRI findings do not suggest cervical invasion, that a simple hysterectomy and bilateral salpingo-oophorectomy may be the best surgical option. However, microscopic cervical infiltration may not be observed by using MRI, and only macroscopic cervical invasion could be found, resulting in low sensitivity for detecting cervical invasion in patients with endometrial carcinoma [55]. A low sensitivity means the missed diagnosis rate (false negative rate) is high. If we only rely on T2WI to judge the cervical invasion, many patients will be missed diagnosis, so that no radical surgical resection will be performed, which will affect the prognosis of patients. Therefore, DCE-MRI is necessary for preoperatively detecting cervical invasion.

According to a recent meta-analysis, DCE-MRI can help improve the sensitivity and specificity for detecting myometrial invasion [55] because DCE-MRI provides the observer with obvious contrast resolution between the markedly enhanced normal myometrium and the moderately enhanced tumour. On DCE-MRI, cervical invasion is defined as the interruption of the normal cervical epithelium enhancement [16]. Moreover, delayed DCE-MRI (4-5 min after the injection) is optimal for the detection of cervical invasion [56]. Previous research reported that DCE-MRI improved the detection of cervical infiltration by endometrial carcinoma [11]. Our meta-analysis also found that, compared with T2WI, DCE-MRI could improve the sensitivity (0.80) and specificity (0.96) of detection. DCE-MRI is accepted as the state-of-the-art standard for tumour delineation and as one of the best approaches for the local staging of endometrial carcinoma [56]. However, it is commonly difficult to assess cervical invasion once endometrial carcinoma spreads to the endocervical canal and begins obliterating the interface between the tumour and the cervix [57]. Other MRI functional imaging techniques are needed for accurate preoperative evaluation of cervical infiltration.
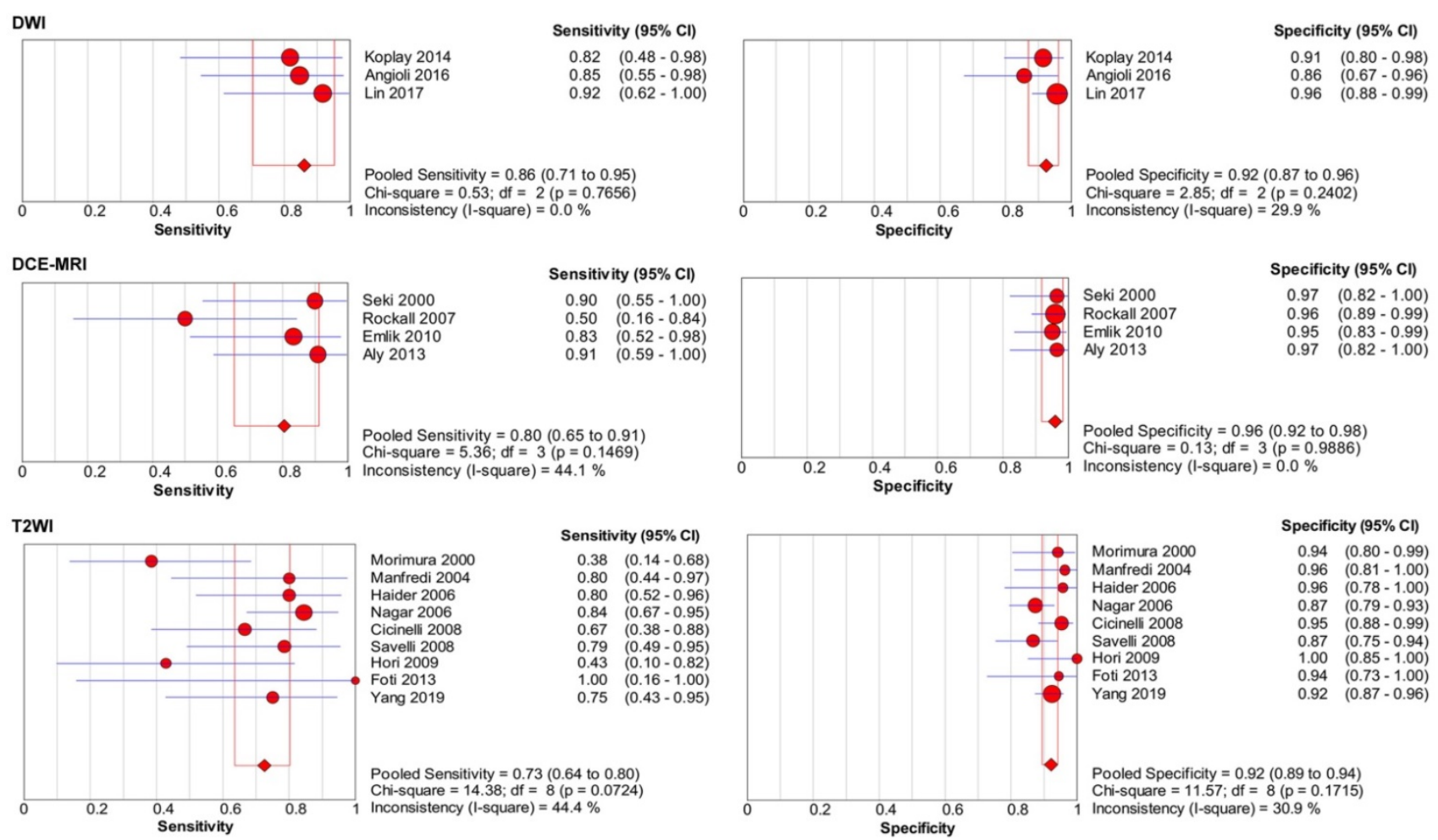

Figure 8. Forest plots of pooled sensitivity and specificity of diffusion weighted imaging (DWI), dynamic contrast-enhanced MRI (DCE-MRI), and T2-weighted imaging (T2WI) for assessing cervical involvement in endometrial carcinoma. $\mathrm{Cl}$, confidence interval. 
DWI is a functional technique of MRI that reflects the diffusivity of the water molecules in tumours. DWI offers potential advantages over DCE-MRI because it does not require contrast administration and it entails a shorter imaging time. Recent evidence suggests that DWI improves the evaluation of the myometrial invasion of endometrial carcinoma because DWI is able to determine malignant lesions as a hyperintense area with excellent tissue contrast [10]. To avoid the influence of the T2 shine-through effect, cervical invasion was defined as the appearance of higher signal intensity on high-b-value DWI and low signal intensity on apparent diffusion coefficient (ADC) maps compared with the surrounding normal cervical parenchyma $[16,56]$. This meta-analysis found that studies that used DWI alone had higher sensitivity $(0.86)$ than studies that used DCE-MRI (0.80) or T2WI (0.73) alone. A significant improvement in the sensitivity was also found in DWI compared with that of DCE-MRI and T2WI for detecting cervical invasion in a previous original study [16]. The false positive rate may increase when cervical mucus is present because mucus shows a high signal on DWI and a low signal on ADC maps, leading to a decrease in specificity. Furthermore, DWI also has other disadvantages, such as limited spatial resolution and image distortions because of susceptibility artefacts. Thus referring to other MR pulse sequences for an anatomical landmark is warranted. As a result, DWI is now routinely used as an adjunct to T2WI and DCE-MRI [56].

There are some limitations in this meta-analysis. First, due to the lack of sufficient supporting literature, sensitivity analyses of other techniques, such as CO2-volumetric interpolated breath-hold examinations, were not performed. Second, some studies did not report the sequences for observing cervical infiltration. In addition, the number of the included studies was limited. It remains to be determined whether combined DWI and T2WI is superior to DCE-MRI and whether a 3.0-T device combined with DWI or DCE-MRI has higher sensitivity and specificity than other devices. Third, publication bias was present among the included studies. One possible reason was that we excluded relevant studies published in other languages. Other possible reasons were that the sensitivity for detecting cervical invasion was low and some articles with negative results might not have been published.

In conclusion, this meta-analysis shows a low pooled sensitivity and high specificity of MRI for detecting any cervical infiltration and stromal invasion in endometrial carcinoma. The studies with a 3.0-T device demonstrated a higher pooled sensitivity than any other study. The higher the field strength was, the higher the pooled sensitivity. Using DWI alone demonstrated higher pooled sensitivity than using DCE-MRI or T2WI only. Studies that used DCE-MRI alone showed higher sensitivity and specificity than those that used T2WI alone.

\section{Abbreviations}

DWI: diffusion-weighted imaging; DCE-MRI: dynamic contrast-enhanced MRI; T2WI: T2-weighted image; ADC: apparent diffusion coefficient; sROC: summary receiver-operating characteristics; CI: confidence interval; PRISMA-DTA: Preferred Reporting Items for Systematic Reviews-Diagnostic Test Accuracy; QUADAS-2: Quality Assessment of Diagnostic Accuracy Studies-2.

\section{Acknowledgements}

This work was partly supported by the Basic Research on Application of Joint Special Funding of Science and Technology Department of Yunnan Province-Kunming Medical University (202001AY070001-110). We sincerely thank Dr Ying Zhao at the Department of MRI, the First People's Hospital of Yunnan Province, the Affiliated Hospital of Kunming University of Science and Technology, for her consistent support of the study.

\section{Competing Interests}

The authors have declared that no competing interest exists.

\section{References}

1. Siegel RL, Miller KD, Jemal A. Cancer statistics, 2019. CA Cancer J Clin. 2019; 69: 7-34.

2. Solmaz U, Mat E, Dereli ML, Turan V, Tosun G, Dogan A, et al. Lymphovascular space invasion and positive pelvic lymph nodes are independent risk factors for para-aortic nodal metastasis in endometrioid endometrial cancer. Eur J Obstet Gynecol Reprod Biol. 2015; 186: 63-7.

3. Taskin S, Ortac F, Kahraman K, Goc G, Oztuna D, Gungor M. Cervical stromal involvement can predict survival in advanced endometrial carcinoma: a review of 67 patients. Int J Clin Oncol. 2013; 18: 105-9.

4. Colombo N, Preti E, Landoni F, Carinelli S, Colombo A, Marini C, et al. Endometrial cancer: ESMO Clinical Practice Guidelines for diagnosis, treatment and follow-up. Ann Oncol. 2013; 24 Suppl 6: i33-8.

5. Xu G, Wang D, Ling X, Lu H, Lin R, Shi $Y$, et al. Diagnostic value of assessment of cervical involvement in early-stage endometrial adenocarcinoma: comparison of magnetic resonance imaging (MRI) versus hysteroscopy. Med Sci Monitor. 2018; 24: 7952-7.

6. Haldorsen IS, Berg A, Werner HM, Magnussen IJ, Helland H, Salvesen OO, et al. Magnetic resonance imaging performs better than endocervical curettage for preoperative prediction of cervical stromal invasion in endometrial carcinomas. Gynecol Oncol. 2012; 126: 413-8.

7. Kinkel K, Kaji Y, Yu KK, Segal MR, Lu Y, Powell CB, et al. Radiologic staging in patients with endometrial cancer: a meta-analysis. Radiology. 1999; 212: 711-8.

8. Yildirim N, Saatli B, Kose S, Sancar C, Ulukus C, Koyuncuoglu M, et al. Predictability of myometrial, lower uterine segment and cervical invasion with 3D transvaginal ultrasonography and magnetic resonance imaging in endometrial cancer patients: a prospective cohort study. Med Ultrason. 2018; 20: $348-54$

9. Haldorsen IS, Salvesen HB. Staging of endometrial carcinomas with MRI using traditional and novel MRI techniques. Clin Radiol. 2012; 67: 2-12.

10. Koplay M, Dogan NU, Erdogan H, Sivri M, Erol C, Nayman A, et al. Diagnostic efficacy of diffusion-weighted MRI for pre-operative assessment of myometrial and cervical invasion and pelvic lymph node metastasis in endometrial carcinoma. J Med Imaging Radiat Oncol. 2014; 58: 538-46, 648. 
11. Aly AM, Moustafa YI, Shaaban HM, Abbas A. Can dynamic contrast enhanced magnetic resonance imaging change treatment planning in endometrial carcinoma? Egypt J Radiol Nucl Med. 2013; 44: 367-73.

12. Hori M, Kim T, Onishi H, Imaoka I, Kagawa Y, Murakami T, et al. Endometrial cancer: preoperative staging using three-dimensional T2-weighted turbo spin-echo and diffusion-weighted MR imaging at $3.0 \mathrm{~T}$ : a prospective comparative study. Eur Radiol. 2013; 23: 2296-305.

13. Emlik D, Kiresi D, Ozdemir S, Celik C, Karakose S. Preoperative assessment of myometrial and cervical invasion in endometrial carcinoma: comparison of multi-section dynamic MR imaging using a three dimensional FLASH technique and T2-weighted MR imaging. J Med Imaging Radiat Oncol. 2010; 54: 202-10.

14. Seki H, Takano T, Sakai K. Value of dynamic MR imaging in assessing endometrial carcinoma involvement of the cervix. Am J Roentgenol. 2000; 175: 171-6.

15. Ytre-Hauge S, Dybvik JA, Lundervold A, Salvesen OO, Krakstad C, Fasmer $\mathrm{KE}$, et al. Preoperative tumor texture analysis on MRI predicts high-risk disease and reduced survival in endometrial cancer. J Magn Reson Imaging. 2018; 48: 1637-47.

16. Lin G, Huang Y, Chao A, Lin Y, Yang L, Wu R, et al. Endometrial cancer with cervical stromal invasion: diagnostic accuracy of diffusion-weighted and dynamic contrast enhanced MR imaging at 3T. Eur Radiol. 2017; 27: 1867-76.

17. Angioli R, Plotti F, Capriglione S, Scaletta G, Dugo N, Aloisi A, et al. Preoperative local staging of endometrial cancer: the challenge of imaging techniques and serum biomarkers. Arch Gynecol Obstet. 2016; 294: 1291-8.

18. Teng F, Zhang YF, Wang YM, Yu J, Lang X, Tian WY, et al. Contrast-enhanced MRI in preoperative assessment of myometrial and cervical invasion, and lymph node metastasis: diagnostic value and error analysis in endometrial carcinoma. Acta Obstet Gyn Scan. 2015; 94: 266-73.

19. Kitajima K, Suenaga Y, Ueno Y, Kanda T, Maeda T, Takahashi S, et al. Value of fusion of PET and MRI for staging of endometrial cancer: Comparison with 18F-FDG contrast-enhanced PET/CT and dynamic contrast-enhanced pelvic MRI. Eur J Radiol. 2013; 82: 1672-6.

20. Ørtoft G, Dueholm M, Mathiesen O, Hansen ES, Lundorf E, Møller C, et al. Preoperative staging of endometrial cancer using TVS, MRI, and hysteroscopy. Acta Obstet Gyn Scan. 2013; 92: 536-45.

21. Antonsen SL, Jensen LN, Loft A, Berthelsen AK, Costa J, Tabor A, et al. MRI, $\mathrm{PET} / \mathrm{CT}$ and ultrasound in the preoperative staging of endometrial cancer-A multicenter prospective comparative study. Gynecol Oncol. 2013; 128: 300-8.

22. Duncan KA, Drinkwater KJ, Frost C, Remedios D, Barter S. Staging cancer of the uterus: a national audit of MRI accuracy. Clin Radiol. 2012; 67: 523-30.

23. Tong $\mathrm{T}$, Yajia G, Huaying $\mathrm{W}$, Weijun P. Application of $1.5 \mathrm{~T}$ magnetic resonance imaging in endometrial cancer. Arch Gynecol Obstet. 2012; 285: $1113-8$.

24. Zamani F, Goodarzi S, Hallaji F, Zamiri A, Deilami $T$, Malek $M$, et al Diagnostic value of pelvic MRI for assessment of the depth of myometrial invasion and cervical involvement in endometrial cancer: comparison of new versus old FIGO staging. Iran J Radiol. 2012; 9: 202-8.

25. Hori M, Kim T, Murakami T, Imaoka I, Onishi H, Nakamoto A, et al. MR imaging of endometrial carcinoma for preoperative staging at $3.0 \mathrm{~T}$ : Comparison with imaging at 1.5 T. J Magn Reson Imaging. 2009; 30: 621-30.

26. Cicinelli E, Marinaccio M, Barba B, Tinelli R, Colafiglio G, Pedote P, et al Reliability of diagnostic fluid hysteroscopy in the assessment of cervical invasion by endometrial carcinoma: a comparative study with transvaginal sonography and MRI. Gynecol Oncol. 2008; 111: 55-61.

27. Sanjuán A, Escaramís G, Ayuso JR, Román SM, Torné A, Ordi J, et al. Role of magnetic resonance imaging and cause of pitfalls in detecting myometrial invasion and cervical involvement in endometrial cancer. Arch Gynecol Obstet. 2008; 278: 535-9.

28. Savelli L, Ceccarini M, Ludovisi M, Fruscella E, De Iaco PA, Salizzoni E, et al. Preoperative local staging of endometrial cancer: transvaginal sonography vs. magnetic resonance imaging. Ultrasound Obstet Gynecol. 2008; 31: 560-6.

29. Nagar H, Dobbs S, McClelland HR, Price J, McCluggage WG, Grey A. The diagnostic accuracy of magnetic resonance imaging in detecting cervical involvement in endometrial cancer. Gynecol Oncol. 2006; 103: 431-4.

30. Akaeda T, Isaka K, Takayama M, Kakizaki D, Abe K. Myometrial invasion and cervical invasion by endometrial carcinoma: Evaluation by $\mathrm{CO} 2$-volumetric interpolated breathhold examination (VIBE). J Magn Reson Imaging. 2005; 21: 166-71.

31. Manfredi R, Mirk P, Maresca G, Margariti PA, Testa A, Zannoni GF, et al. Local-regional staging of endometrial carcinoma: role of MR imaging in surgical planning. Radiology. 2004; 231: 372-8.

32. Frank RA, Bossuyt PM, McInnes M. Systematic reviews and meta-analyses of diagnostic test accuracy: the PRISMA-DTA statement. Radiology. 2018; 289: 313-4

33. Whiting PF, Rutjes AW, Westwood ME, Mallett S, Deeks JJ, Reitsma JB, et al. QUADAS-2: a revised tool for the quality assessment of diagnostic accuracy studies. Ann Intern Med. 2011; 155: 529-36.

34. Zamora J, Abraira V, Muriel A, Khan K, Coomarasamy A Meta-DiSc: a software for meta-analysis of test accuracy data. Bmc Med Res Methodol. 2006; 6: 31 .

35. Higgins JP, Thompson SG, Deeks JJ, Altman DG. Measuring inconsistency in meta-analyses. BMJ. 2003; 327: 557-60.
36. Deeks JJ, Macaskill P, Irwig L. The performance of tests of publication bias and other sample size effects in systematic reviews of diagnostic test accuracy was assessed. J Clin Epidemiol. 2005; 58: 882-93.

37. Undurraga M, Petignat P, Pelte M, Jacob S, Dubuisson J, Loubeyre P. Magnetic resonance imaging to identify risk of lymph node metastasis in patients with endometrial cancer. Int J Gynecol Obstet. 2009; 104: 233-5.

38. Celik C, Ozdemir S, Kiresi D, Emlik D, Tazegul A, Esen H. Evaluation of cervical involvement in endometrial cancer by transvaginal sonography, magnetic resonance imaging and frozen section. J Obstet Gynaecol. 2010; 30: 302-7.

39. Foti PV, Farina R, Coronella M, Ruggeri C, Palmucci S, Montana A, et al. Endometrial carcinoma: MR staging and causes of error. La radiologia medica. 2013; 118: 487-503.

40. Morimura $\mathrm{Y}$, Soeda $\mathrm{S}$, Hashimoto $\mathrm{T}$, Takano $\mathrm{Y}$, Ohwada $\mathrm{M}$, Yamada $\mathrm{H}$, et al. The value of pre-operative diagnostic procedures for cervical involvement in uterine corpus carcinoma. Fukushima J Med Sci. 2000; 46: 1-11.

41. Cunha TM, Felix A, Cabral I. Preoperative assessment of deep myometrial and cervical invasion in endometrial carcinoma: comparison of magnetic resonance imaging and gross visual inspection. Int J Gynecol Cancer. 2001; 11: 130-6.

42. Haider MA, Patlas $M$, Jhaveri $K$, Chapman $W$, Fyles A, Rosen B. Adenocarcinoma involving the uterine cervix: magnetic resonance imaging findings in tumours of endometrial, compared with cervical, origin. Can Assoc Radiol J. 2006; 57: 43-8.

43. Rockall AG, Meroni R, Sohaib SA, Reynolds K, Alexander-Sefre F, Shepherd $\mathrm{JH}$, et al. Evaluation of endometrial carcinoma on magnetic resonance maging. Int J Gynecol Cancer. 2007; 17: 188-96.

44. Vasconcelos C, Felix A, Cunha TM. Preoperative assessment of deep myometrial and cervical invasion in endometrial carcinoma: comparison of magnetic resonance imaging and histopathologic evaluation. J Obstet Gynaecol. 2007; 27: 65-70.

45. Cabrita S, Rodrigues H, Abreu R, Martins M, Teixeira L, Marques C, et al. Magnetic resonance imaging in the preoperative staging of endometrial carcinoma. Eur J Gynaecol Oncol. 2008; 29: 135-7.

46. Hahn H, Song H, Lee I, Kim T, Lee K, Shim J, et al. Magnetic resonance imaging and intraoperative frozen sectioningfor the evaluation of risk factors associated with lymph node metastasis in endometrial cancer. Int J Gynecol Cancer. 2013; 23: 1411-6.

47. Yin $\mathrm{X}$, Jia H, Shi M, Wu H, Li Y. Magnetic resonance imaging for detection of depth of myometrial invasion and cervical invasion in patients with endometrial carcinoma. Int J Clin Exp Med. 2015; 8: 19501-5.

48. Zamani N, Modares GM, Zamani F, Zamani MH. Utility of pelvic MRI and tumor markers HE4 and CA125 to predict depth of myometrial invasion and cervical involvement in endometrial cancer. J Family Reprod Health. 2015; 9: 177-83.

49. Shrivastava S, Barmon D, Kataki AC, Deka P, Sharma JD, Choudhary BK, et al. Magnetic resonance imaging in pre-operative staging of endometrial cancer. Indian J Cancer. 2016; 53: 181-5.

50. Chan C, Shek S, Kwok S, Wong WK, Wong T, Fung D, et al. Diagnostic accuracy of preoperative magnetic resonance imaging in staging endometrial cancer: a five-year experience. Hong Kong J Radiol. 2017; 19: 249-55.

51. Rahmani M, Heydari S, Mousavi A, Ahmadinejad N, Azhdeh S, Shakiba M. Accuracy of imaging in preoperative local staging of endometrial cancer: could imaging predict low risk patients? Int J Women's Health Reprod Sci. 2018; 6: 363-8.

52. Goel G, Rajanbabu A, Sandhya CJ, Nair IR. A prospective observational study evaluating the accuracy of MRI in predicting the extent of disease in endometrial cancer. Indian J Surg Oncol. 2019; 10: 220-4.

53. Yang T, Tian S, Li Y, Tian X, Wang W, Zhao J, et al. Magnetic resonance imaging (MRI) and three-dimensional transvaginal ultrasonography scanning for preoperative assessment of high risk in women with endometrial cancer. Med Sci Monitor. 2019; 25: 2024-31.

54. Eskander RN, Randall LM, Berman ML, Tewari KS, Disaia PJ, Bristow RE. Fertility preserving options in patients with gynecologic malignancies. Am J Obstet Gynecol. 2011; 205: 103-10.

55. Bi Q, Chen Y, Wu K, Wang J, Zhao Y, Wang B, et al. The diagnostic value of MRI for preoperative staging in patients with endometrial cancer: a meta-analysis. Acad Radiol. 2020;27(7):960-8.

56. Nougaret S, Horta M, Sala E, Lakhman Y, Thomassin-Naggara I, Kido A, et al. Endometrial cancer MRI staging: Updated Guidelines of the European Society of Urogenital Radiology. Eur Radiol. 2019; 29: 792-805.

57. Freeman SJ, Aly AM, Kataoka MY, Addley HC, Reinhold C, Sala E. The revised FIGO staging system for uterine malignancies: implications for MR imaging. Radiographics. 2012; 32: 1805-27. 